\title{
USING PRESERVATIVE TREATED WOOD FOR TIMBER STRUCTURES IN AQUATIC AND SENSITIVE ENVIRONMENTS
}

\author{
ROBERT BERNHARDT JR. \\ Senior Program Manager, Western Wood Preservers Institute, USA
}

\begin{abstract}
Timber structures located near water and sensitive environments face increased threats of deterioration from decay fungi, marine borers and insects. These include bridges, bulkheads, piers, docks, foundation pilings and other structures. Preservative treated timber products have a long history of providing creative, economical and sustainable design options for such structures featuring effective protection against such threats. Concerns about the potential impacts of the wood preservatives on the environment can be addressed through a systematic approach of evaluating risks, utilizing applicable mitigating measures and managing aspects of the timber product selection, preservative choice and installation. The U.S. wood treating industry has developed a number of tools to guide preservative selection for such projects based on the specific conditions, including an online Environmental Assessment Model and a Best Management Practices program. When these measures are properly considered on a projectbasis, there is a high probability that the preserved timber will have a long service life and potential risks will be minimal and manageable for environmentally safe use.

Keywords: treated wood, preserved wood, timber, preservatives, wood preservation, pressure treated, impregnated, durability, sustainability.
\end{abstract}

\section{INTRODUCTION}

Wood, or timber, has been used for centuries in building a variety of structures to meet civilization's basic needs. Timber offers many positive attributes as a building material. However, when exposed to outdoor conditions, the risks of timber deterioration from decay fungi and insects increases significantly, reducing its service life.

Over the past century, there has been much success in protecting timber for such applications. This has been accomplished by using preservatives impregnated into the wood to protect against degradation while extending its service life from years to decades.

Timber is a natural material and part of its life cycle is a process of biological agents breaking down the wood fiber to return it to the earth as organic material. Under this process, organisms need four basic requirements: adequate moisture, oxygen, adequate temperature and a food source, which is the timber. Organisms that act to destroy the timber include bacteria, fungi, insects, marine borers and some vertebrates such as woodpeckers.

Other agents can degrade timber as well, such as: mechanical damage from handling or in-service abrasion; exposure to ultraviolet light that breaks down the lignin near the wood surface, causing the timber to erode away by wind or water over time; prolonged heat exposure that breaks down wood polymers; exposure to chemicals such as strong acids and bases; and repeated wetting and drying in salt water causing surface damage to the timber, with the cells absorbing so much salt they burst.

Structures constructed of timber, from bulkheads and pilings to bridges and marine facilities, are typically exposed to conditions that pose the highest threat to performance of the products. Timber can be protected by impregnating preservatives into the fiber through pressure treatment, ensuring the protection remains in place when splits, abrasion and other 
in-service changes impact the wood. Preserved timber structures provide an environmental and cost-effective solution that extends the durability and in-service life.

Compared to other building materials, preserved timber offers many inherent environmental benefits that should be considered when making product selection decisions. One key benefit is that wood is a renewable and sustainable material, as timber can be harvested, replanted, regrown and harvested again. Over the past half century, the ability to manage the global forest resource - particularly in Europe and the U.S. - has advanced in a way that balances the need for timber with other important values such as wildlife, water and species diversity.

Other benefits of preserved timber are documented in a series of quantitative environmental impact evaluations conducted by the U.S. wood treating industry through the Treated Wood Council. These evaluations reviewed the associated production, use and disposition of various preserved timber products compared to alternative materials such as steel, concrete and plastic composites.

The evaluations determined that in seven out of eight key environmental impact indicators, preserved timber required less total energy and less fossil fuel, had lower overall environmental impacts and, when reused for energy recovery in permitted facilities with appropriate emission controls, would reduce greenhouse gas levels in the atmosphere. The evaluations were conducted using Life Cycle Assessment (LCA) methodologies that followed ISO 14044 standards and were peer-reviewed and published in U.S. national journals. Summary information and links to the full LCA reports are available online [1].

\section{IMPREGNATING WOOD PRESERVATIVES}

Timber is a unique material that is well suited to accept preservative chemicals that provide a barrier against wood-destroying agents while maintaining its structural integrity. The cellular structure of the fiber resembles a series of hollow tubes, which act to move water and nutrients through the tree as it grows.

When the timber is converted into a product, whether sawn or round, this cell structure can allow liquid preservatives to be transferred into the fiber through a pressure process. These preservatives fixate or remain infused into the wood to discourage biological agents from breaking down the fiber.

Preservatives used for timber in the United States are fully regulated by the U.S. Environmental Protection Agency (EPA) under the Federal Insecticide, Fungicide and Rodenticide Act (FIFRA). Wood preservatives are required to undergo a rigorous registration and re-registration process. The EPA considers wood preservative systems as antimicrobial pesticides and requires the pesticides be supported with thorough scientific review and analysis. It also must be shown the preservatives can be used without causing adverse effects to human health or the environment.

Preservatives used in commercial wood treating are differentiated by the carrier used to infuse: waterborne or oil-type. In some cases, the carrier itself offers protective qualities.

Both preservative types are infused into the wood fiber using the same process. Untreated timber is loaded onto carts, which are moved into a specially made cylinder called a retort. The retort, which can be up to 150 feet (46 meters) in length, is sealed with the wood inside and a vacuum is applied to remove air.

Preservative solution is pumped from storage tanks, completely filling the retort. Pressure is continuously applied within the retort to force preservative into the cells of the wood. Processing time depends on the timber species, the size of the products treated and the preservative used, as well as the retention or amount of preservative in the wood required for the intended exposure of the final product. 
The preservative is drained from the retort and a vacuum applied to return the excess solution to storage tanks for future use. Carts are moved out of the retort onto a sealed drip pad to reclaim any residual preservative on the timber.

Representative core samples are taken and analyzed to ensure quality and durability standards, such as retention and penetration, are met. Third-party inspection agencies also take core samples during regular visits to confirm the plant's quality control practices.

The finished preserved timber products are typically covered with a top wrap and moved to a storage area for shipping.

\section{PLANNING FOR APPROPRIATE USE OF PRESERVATIVE TIMBER}

Timber structures may be sited near, over or in some form of water body, wetland or drainage. If the timber condition changes, the potential for movement of preservative into the environment is possible. As such, the preserved timber in these structures pose varying degrees of environmental risk when constructed and maintained.

Given this risk, it is important to understand the science behind wood preservative systems and how to select and manage the use of preserved timber to ensure the desired performance while minimizing the potential risk for any adverse environmental impacts. The process begins at project conception and follows through installation and maintenance.

There are five basic steps when planning for preserved timber used in aquatic and sensitive environments with exposure to fresh or salt water:

1. Selecting the proper preservative

2. Environmental considerations and evaluations

3. Specifying best management practices

4. Requiring quality assurance and certification

5. Following specifier responsibilities for handling, installation and maintenance

\subsection{Selecting the proper preservative}

It is important to fully understand how to identify and specify the appropriate wood preservative system based on the timber species and existing environment on the project site. Resources that provide helpful information include the wood preservation section in the USDA Forest Products Laboratory's Wood Handbook [2].

Western Wood Preservers Institute (WWPI) offers guidance documents on the use of preservatives in aquatic and wetland environments [1] and in the Treated Wood Guide smartphone app (iOS and Android). Information on preservatives for specific exposures is available in the American Wood Protection Association (AWPA) Book of Standards - Use Category System Standard U1, Sections 3, 4 and 5 [3].

The AWPA Book of Standards identifies 27 different wood preservative systems; however only eight are commonly used to preserve timber designated for use in aquatic and wetland environments either in or over fresh and salt water. There are a few other proprietary formulations available that are often selected for aesthetic purposes, but these are not discussed in this paper.

The eight commonly available preservatives for use in aquatic and wetland environments can be segregated into two general categories: waterborne and oil-type systems.

\subsubsection{Waterborne preservative systems}

Waterborne systems are considered inorganic preservatives and are characterized by the fact that water is the primary carrier of the preservative into the wood fiber. In these systems, the preservatives are infused through pressure into the wood substrate and become attached or 
fixed to the wood cells, minimizing migration once the chemical is stabilized. All waterborne preservatives perform basically the same and leave a dry and paintable surface.

The primary concern with waterborne preservatives is the potential environmental effect the loss of copper and other chemicals from the preservatives will have on the specific project environment when placed into service.

The four main waterborne systems or groups used in aquatic and wetland environments are:

- Ammoniacal Copper Zinc Chromate (ACZA) - Marketed under the trade name Chemonite ${ }^{\circ}, A C Z A$ is an ideal preservative for hard-to-treat species. Thanks to this quality and its environmental record, ACZA is normally the preservative of choice to treat U.S. coastal Douglas fir and Hem-Fir for uses such as piling, bulkheads and bracing that will be immersed or come into contact with fresh or salt water. In some areas, use of ACZA products is restricted because of perceived environmental risk associated with short-term migration of the preservative from the timber. These restrictions may include additional mitigating measures, such as wrapping or coating, to stop or minimize the loss of preservative or protect against loss of the treated wood through abrasion. ACZA is also commonly used in a variety of other above water applications.

- Alkaline Copper Quat (ACQ), Copper Azole (CA) and Micronized Copper Azole (MCA) - These preservatives are widely used throughout the U.S. in a variety of residential, commercial and certain agricultural applications and are typically considered as "general use" preservatives. ACQ, CA and MCA preserved timber products are commonly used over and in fresh water or when subject to brackish or saltwater splash. The exception is that ACQ-preserved round and sawn timber piling also can be used for land and in freshwater applications. As with ACZA, there is an environmental concern by some permitting agencies over the potential loss of copper from these preservatives and the perceived effects it may have on the specific project environments. However, with some exceptions, products preserved with ACQ, CA and MCA are generally viewed favorably for general use in or above freshwater or near saltwater applications.

- Chromated Copper Arsenate (CCA) - Since 2004 in the U.S., CCA only has been available for use in preserved timber products identified for commercial and/or industrial use. In Europe, CCA is not allowed for use in treating timber. While CCA preserved timber products are readily produced throughout the U.S., use of these products near, in or over bodies of water are largely discouraged or prohibited by permitting agencies, even though it has been demonstrated the environmental risks are minimal.

3.1.2 Oil-type preservative systems

Oil-type preservatives are organic preservatives that are 100\% active (Creosote) or dissolved in an oil-based solvent. These mixtures fill or coat the wood cells walls during treatment.

The three primary oil-type systems used in aquatic and wetland environments are:

- Creosote - This was one of the first commercial wood preservatives and is manufactured by the distillation of tar obtained from coal. It typically has some odor and is not paintable. Primary use is in treatment of industrial products such as railway ties, utility poles, cross arms, piling and timbers for bridges and other transportation structures. Creosote preserved timber can be used in a variety of applications for in-ground contact and in or over fresh and salt water. Creosote has 
a long history as a very effective preservative and it is not uncommon to find marine piling and bridge structures today in good serviceable condition with ages ranging from 50 to 90 years. Creosote is almost exclusively used in the U.S. to treat railway ties for American railroads, representing approximately $95 \%$ of the creosote used today in the country.

- $\quad$ Pentachlorophenol (PCP) - Commonly referred to as Penta, this preservative in a solid state is dissolved in petroleum oil, either in diesel or fuel oil grades and light hydrocarbon solvents. Penta is diluted between $5 \%$ to $10 \%$ in oil for use as a preservative solution. Use of Penta is popular for preserving timber utility poles and cross arms in North America, as well as solid timber and laminated timbers used in construction of buildings and bridges. In the U.S., Penta-preserved material in aquatic applications are restricted to above water structures in salt water and in or above fresh water. In most European countries, the use of Penta is not allowed for wood preservation.

- Copper Naphthenate $(\mathrm{CuN})$ - This preservative is different than other copper-based preservatives in that the copper is reacted with naphthenic acid, a hydrocarbon byproduct of crude oil processing. The $\mathrm{CuN}$ concentrate is diluted with fuel oil at treating plants to make the preservative solution. Unlike other oil-type preservatives used in the U.S., CuN is not a restricted pesticide under the EPA. CuN is used to preserve a variety of products for industrial projects such as foot and vehicle bridges, as well as fence rails and posts, guardrail posts, railroad ties, utility poles and outdoor recreational structures. While restricted from use in brackish or salt water applications, $\mathrm{CuN}$ can be used to preserve a variety of timber materials used near salt water or in and above ground for freshwater applications.

In addition to the above, many other factors may come into play when selecting the appropriate preservative system. Managers will likely weigh the economics, type of project, availability of timber species, aesthetics, environmental concerns and the permitting or approval process itself. These decisions will be influenced by the permitting authority, existing laws, personal preference, organizational policy, professional knowledge and environmental conditions.

\section{ENVIRONMENTAL CONSIDERATIONS AND EVALUATION}

When designing a timber project, the characteristics of various preserved timber products should be taken into consideration in relation to the purpose of the project and the environmental conditions at the project site.

Products used in an industrial application, like a bridge for motor vehicles, will likely be different from those used in a public structure such as a dock, marina or boardwalk. Similarly, the use of a moderate amount of preserved timber in a fast-flowing river or stream is likely to pose a minimal environmental impact, while the use of large amounts of preserved timber in somewhat stagnant water may pose greater risk.

All common construction materials used in aquatic applications - including wood, steel, concrete and plastic - will introduce some degree of chemical into the environment. The extent of the impact of these releases will depend on whether they are present in large enough concentrations.

For preservative-treated timber in an exposed environment, it is anticipated the timber condition will change, allowing a certain amount of preservative to migrate from the timber. Typically, this only take places for a short period of time just after installation, and the migrating preservative enters the water column or sediment adjacent to the project area. 
Thus, it is important to evaluate the level of potential risk on a site-specific basis to determine the best ways to properly manage the risks.

There are projects where the use of preserved timber may be of significant environmental concern, for example when used in or near previously contaminated waters or in very slowmoving waters with no natural flushing. However, based on scientific studies and field results in the U.S. and Canada, 95\% of projects where preserved timber is used in some type of aquatic environment do not significantly impact that environment when the risks are identified and managed.

\subsection{Environmental assessment modelling}

Creating models to predict the potential outcomes based on theory, empirical data and specific inputs are done in many branches of science. The sophistication of these models can vary from simple to very complex.

Using a model to predict an outcome with $100 \%$ accuracy is impossible, as accuracy depends on the complexity of the dynamics of all elements within the model. For example, the dynamics of the atmosphere make it difficult to make fully accurate weather forecasts, despite the extensive data and calculating capacity available today.

In light of these limitations, it's important to note that models don't have to be right to be useful. Models created for assessing risk in using preserved timber were designed to conservatively predict specific sites where pressure-treated timber projects have a reasonable probability of creating environmental impacts.

\subsubsection{Preserved timber environmental assessment model}

The Environmental Assessment Model for preserved timber was developed based on research conducted by Dr. Kenneth M. Brooks [4]. Given the dynamics of assessing risk for aquatic environments, the model was designed to conservatively predict specific sites where pressure-treated timber projects have a reasonable probability of creating an unacceptable environmental risk.

A detailed discussion of the models and supporting information on preserved timber products that can be used safely in aquatic environments when the risks are evaluated can be found in Treated Wood in Aquatic Environments, published by WWPI [5].

The model was extensively peer reviewed and earned recognition by the U.S. National Oceanic and Atmospheric Administration - Fisheries (NOAA-Fisheries) to help biologists and project proponents of preservative-treated timber evaluate the potential environmental effects. NOAA further codified use of the model in a guidance document [6].

In addition to the risk assessment models, a simplified Level One Screening Assessment tool is available to assist in making evaluations of the environmental risks for small projects. This simplified assessment tool is based on the science used to develop the more robust risk assessment model. It utilizes tables and basic project site condition information to easily make preliminary predictions, based on a worst-case scenario, on whether a more extensive risk assessment should be undertaken, or support a conclusion there is no significant environmental effect from using preserved timber on a project [7].

\subsubsection{Online environmental assessment model}

The original Environmental Assessment Model was created as a Microsoft Excel ${ }^{\circledR}$ spreadsheet, which allowed evaluation of structures above and below water built with timber treated with the most commonly used preservatives [8]. 
In 2015, WWPI commissioned the development of a more user-friendly online Environmental Assessment Model. Work on the model was completed in late 2016 and posted online in February 2017 in cooperation with the Oregon State University (OSU) Environmental Performance of Treated Wood Research Cooperative [9].

Utilizing modern programming, the model provides more dynamic, streamlined data entry as well as more flexible definition of benchmarks. Inputs can be made in Imperial as well as metric measurements.

Site specific conditions that can be defined in the online model include the physical setting of the project such as the type of water body (freshwater or marine - salt water), the velocity of the current in the water body, water depth, rainfall, sediment characteristics, $\mathrm{pH}$, water temperature and other background water quality characteristics. In the event any of these parameters are unknown for a project, the default values listed are chosen to produce conservative results.

With the online model completed, WWPI and OSU will conduct workshops for public agencies, consultants and industry personnel involved in project planning, assessing aquatic environmental effects and/or permitting approval processes.

\section{APPLICATION OF BEST MANAGEMENT PRACTICES FOR PRESERVED WOOD}

In addition to modelling, another key element available in managing risk with preserved timber products is specification of WWPI's Best Management Practices for Use of Preservative Wood in Aquatic and Wetland Environments (BMPs) [10]. BMPs are additional wood preserving guidelines for individual or groups of preservative systems used to treat timber designated for aquatic or wetland environments.

Specification of the BMPs gives designers assurance that timber materials manufactured for a project have been preserved with the minimal level of preservative needed for protection

\section{(e) Environmental Assessment Modelling Tool}

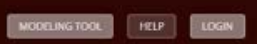

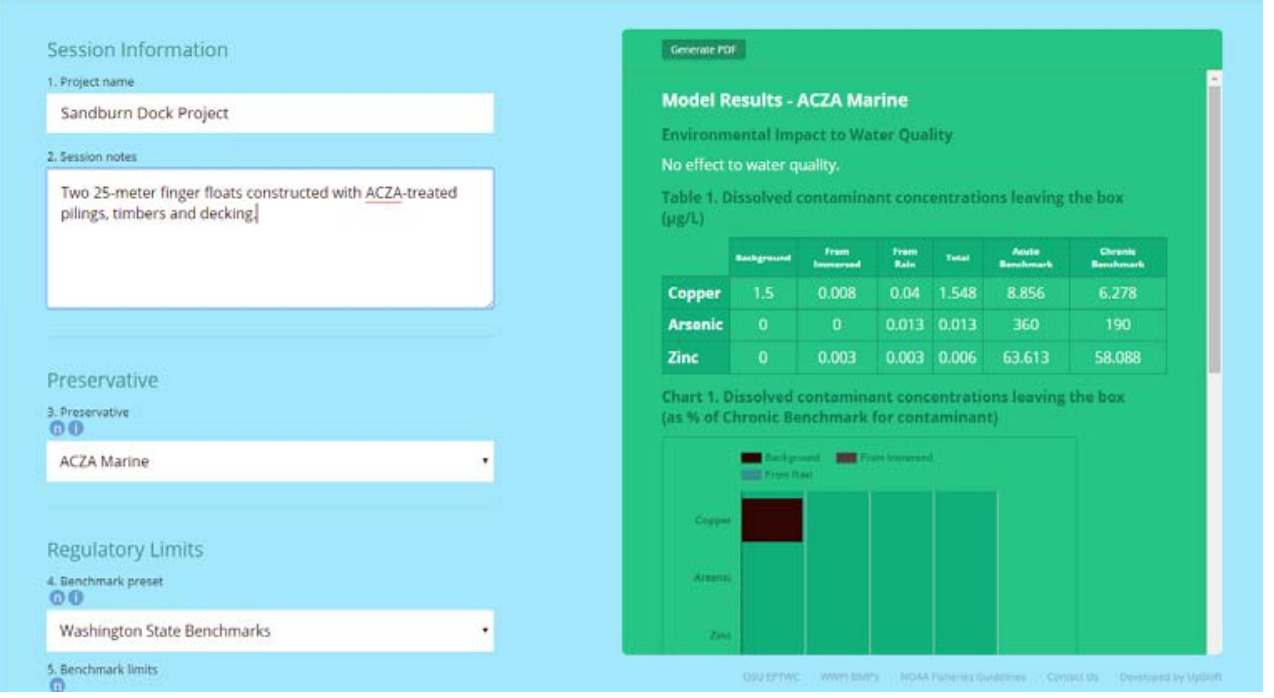

Figure 1: The Online Environmental Assessment Modelling Tool provides a user-friendly interface and can generate reports and documentation for submission to regulators or government agencies [9]. 
that reduces the amount potentially available for migration into the environment.

BMPs are separate from and in addition to AWPA treating standards. There is a shared responsibility between the Specifier and Treater to assure the preservative system application selected will meet the goal of minimizing the migration of the preservative into the environment.

\subsection{BMPs for treated timber production}

Manufacturing of BMP Qualified Timber Products must conform to specific practices as outlined for each listed preservative. The overall objective of all of these production practices is to provide the needed level of protection while minimizing the amount of the preservative available for potential movement into the environment.

The required practices to achieve the BMP objectives are unique for each preservative. Specific practices for each preservative are listed for the following categories:

- Preservative

- Treatment processes

- Post-treatment procedures

- Technical notes

General requirements are also defined for plant and product cleaning, processing and record keeping.

\subsection{Quality assurance and certification}

One of the benefits of specifying timber material to be preserved according to the BMPs is required third-party independent inspection procedures and certification. These are in place to assure the material meets treating standards and the BMP guidelines.

To assure timber products meet AWPA standards, it is important that the presence of a quality mark be present on all structural product labels or in a letter of certification, should labelling not be present.

The presence of the CheckMark ${ }^{\circledR}$ logo (Fig. 2) is a quick and simple way of identifying whether the timber purchased has been inspected by an approved American Lumber Standard Committee (ALSC) third-party inspection agency authorized to assure compliance with AWPA standards.

Additionally, to assure material has been preserved in accordance with the BMP guidelines, certification also should be verified by a letter of certification from an authorized third-party inspection agency or the presence of the WWPI BMP Certification Mark (Fig. 3) on the product or unit.

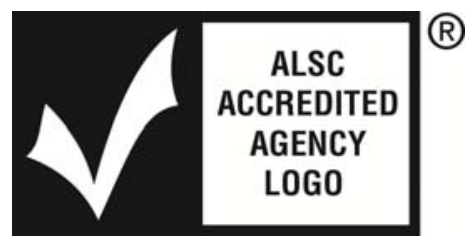

Figure 2: CheckMark symbol indicating the timber has been treated to American Wood Protection Association standards and has been inspected by an approved American Lumber Standard Committee (ALSC) third-party inspection agency. 


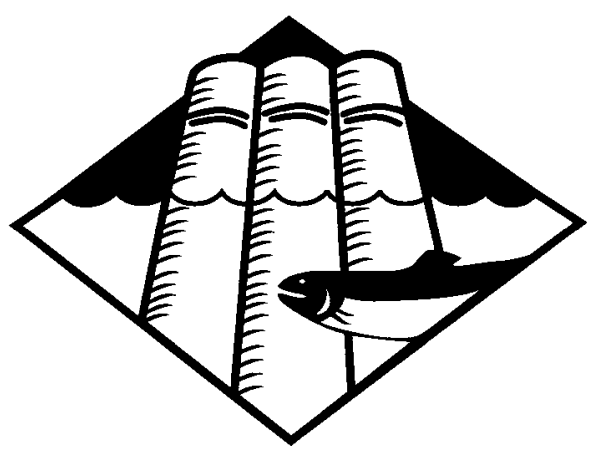

Figure 3: BMP Certification Mark, which can appear on the product or in documentation assures the timber has been produced according to the BMPs and properly inspected.

Details on the quality assurance inspection procedures and requirements are incorporated in the BMP guide [10].

It is not recommended for a specifier or regulator to designate a BMP treatment process for a product. It is the quality of the final product that matters, as there is often more than one method of meeting performance goals that are dependent on many factors. How the end result is achieved should be left to the manufacturer.

\subsection{BMP specifier responsibilities, installation, handling}

Achieving the shared goal of the BMPs cannot be accomplished unless the user of the product follows the appropriate guidelines covering how the products should be stored, installed and maintained. These guidelines cover the following areas:

- Design and purchasing

- Transportation

- Inspection, acceptance, rejection

- Storage

- Installation, handling

- Field treating

- Demolition

- Disposal

Each of the guidelines are intended to secure against release of preservative into the environment and any potential compromises of the preservative protection in the timber. The detailed guidelines for each area can be reviewed in the BMP manual [10].

\section{CONCLUSION}

Preserved timber has played an essential role in the economic prosperity and quality of life in North America for more than a century. Timber pressure treated with preservatives has been the preferred, time-proven, cost effective material of choice, from rail ties and utility poles to bridges and structures used for commercial, industrial and recreation applications.

In more recent decades, there have been many laws and regulations adopted seeking to protect the environment. This has increased the scrutiny and awareness of the use of 
preserved timber in aquatic and sensitive environments, at times leading to restrictions on how and where these products should be used.

At the same time, preserved timber products have been used in such areas for decades with scientific reports documenting no adverse environmental impacts. The preserved timber industry has taken action to better understand the environmental effects of wood preservative systems to determine the proper applications and assure they could be environmentally safe to use.

This has led to the advent of new, science-based tools and practices which have fostered a better understanding of how best to manage any potential risks associated with using preserved timber in such environments. These tools and practices will continue to be refined through research and monitoring of the effectiveness of such measures.

[1] www.PreservedWood.org

\section{REFERENCES}

[2] Bergman, R. et al., Wood Handbook, Wood as an Engineering Material, USDA Forest Products Laboratory, 2010, Online. https://www.fpl.fs.fed.us/products/publications/ specific pub.php?posting id $=18102 \&$ header $\mathrm{id}=\mathrm{p}$

[3] American Wood Protection Association, AWPA Book of Standards, 2016.

[4] Morrell, J., Brooks, K. \& Davis, C., Managing Treated Wood in Aquatic Environments, Forest Products Society, Chapter 9, 2011, Online. http://preservedwood.org/portals/0/ documents/Chapter9_Brooks.pdf

[5] Western Wood Preservers Institute, Treated Wood in Aquatic Environments, 2012, Online. http://preservedwood.org/portals/0/documents/TW_Aquatic_Guide.pdf

[6] NOAA Fisheries, Use of Treated Wood Products in Aquatic Environments: Guidelines to West Coast NOAA Fisheries staff for Endangered Species Act and Essential Fish Habitat Consultations in the Alaska, Northwest and Southwest Regions, 2009, Online. http://preservedwood.org/portals/0/documents/NOAA_guidelines.pdf

[7] Western Wood Preservers Institute, Screening Level Assessment Process and Worksheets, 2011, Online. http://preservedwood.org/portals/0/documents/ ScreeningLevelAssessment.pdf

[8] Western Wood Preservers Institute, Environmental Assessment Model - Excel, 2010, Online. http://preservedwood.org/portals/0/documents/AquaticAssessmentModel.zip

[9] OSU-WWPI, Online Environmental Assessment Modelling Tool, 2017, Online. $\mathrm{http}: / /$ wwpi.forestry.oregonstate.edu/

[10] Western Wood Preservers Institute, Best Management Practices for Use of Preservative Wood in Aquatic and Wetland Environments, 2012, Online. http://preservedwood.org/ portals/0/documents/BMP.pdf 